\title{
Investigation on upsetting assisted by low-frequency vibration
}

\author{
M. Zhang, P. Li, D. Yao, L. Deng, J.S. Jin, and X.Y. Wang ${ }^{\mathrm{a}}$ \\ State Key Laboratory of Materials Processing and Die \& Mould Technology, Huazhong University of \\ Science and Technology, 1037 Luoyu Road, 430074 Wuhan, Hubei, China
}

\begin{abstract}
The application of vibration load in metal forming processes has been demonstrated to be effective in reducing the forming load. In this paper, upsetting processes assisted by low-frequency vibration at room temperature was investigated based on finite element simulations. The vibration load was applied by the reciprocating movement of the upsetting punch. The influence of vibration frequency and feeding rate were analysed. It was revealed that low-frequency vibration was effective to reduce the mean forming load and increase the friction between billets and tools.
\end{abstract}

\section{Introduction}

By applying vibration load in the metal plastic forming processes, the deformation resistance can be reduced significantly, and the surface quality of manufactured products can be obviously improved $[1,2]$. Many studies have been carried out concerning forming processes assisted by ultrasonic loads, since ultrasonic has energy densities high enough to activate structural evolutions inside specimens, as well as at the interface between specimens and tools [3-6]. Hung et al. discussed the frictional effect of ultrasonic vibration on the upsetting of aluminium alloy, and found that the flow stress is reduced while the interfacial friction is increased due to the temperature rise caused by ultrasonic vibration [4]. Ashida et al. used ultrasonic vibration to avoid wrinkling and cracking in press forming caused by friction between sheet metal and dies, and got favourable results [5]. Huang et al. presented a study of the influence of ultrasonic on the boundary conditions associated with the equipment walls in a soft solid forming process using plasticine as the material model. They explained the force reduction based on both the stress superposition effect and the thermal reduction of the interface friction [6]. Bunget et al. investigated the possibility of applying ultrasonic vibrations in the micro-extrusion process, and found a significant drop in the forming load and also an obvious improvement of the micro-formed part surface [7]. Even after being investigated for more than 50 years, there are still many disagreements about the softening mechanism of vibration loading. In previous studies, it is explained by one or several possible mechanisms, such as absorption of acoustic energy at dislocations [8], reduction of internal and contact friction [9], dynamic effects of high frequency vibrated tools and thermal effects $[4,10]$.

\footnotetext{
${ }^{\text {a }}$ Corresponding author: wangxy_hust@163.com
}

This is an Open Access article distributed under the terms of the Creative Commons Attribution License 4.0, which permits unrestricted use, distribution, and reproduction in any medium, provided the original work is properly cited. 


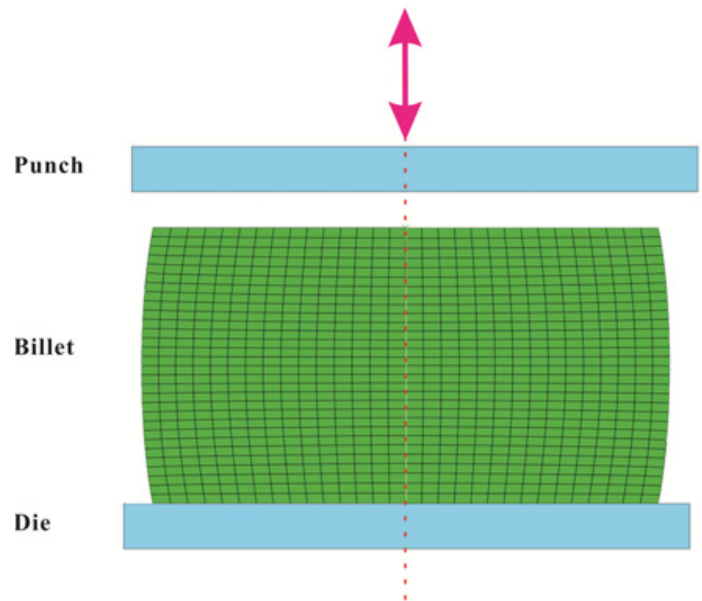

(a)

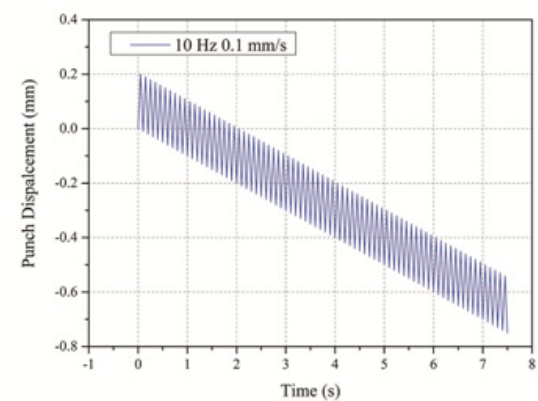

(b)

Figure 1. (a) Schematic diagram of the upsetting process; (b) an example of the vibration motion of the punch.

In this paper, the vibration-assisted upsetting process of brass cylinders at room temperature was investigated based on numerical simulation. The upsetting punch vibrated at low frequencies in a displacement-controlled way. The influence of vibration frequency and feeding rate on the deformation behaviour of brass specimens was discussed, in order to reveal the action mechanism of vibrationassisted forming.

\section{Methods}

Numerical simulations of the low-frequency vibration assisted upsetting of brass cylinders were carried out using Abaqus/Explicit. A 3D finite element model with a diameter of $1 \mathrm{~mm}$ and a height of $1.5 \mathrm{~mm}$ was constructed and meshed with C3D8R elements, as shown in Fig. 1a. Due to symmetry, only a quarter of the model was simulated with 8200 elements. The material was set as the pure brass selected from the material library of Abaqus. The forming temperature was set as $20^{\circ} \mathrm{C}$. The friction between specimens and tools was defined as Coulomb friction with the friction coefficient set as 0.08 . The feeding rate of the punch was $0.01,0.05$ and $0.1 \mathrm{~mm} / \mathrm{s}$. Vibration with an amplitude of $0.1 \mathrm{~mm}$ was superimposed on the punch, and the frequency was set as 10, 20, 40 and $80 \mathrm{~Hz}$. An example of the time-displacement curves of the upsetting punch is displayed in Fig. 1b. The deformation amount for all the conditions was $50 \%$, i.e. the punch stroke was $0.75 \mathrm{~mm}$.

\subsection{Results and discussions}

\subsubsection{Influence of vibration frequency}

The influence of vibration frequency on the forming load of the vibration-assisted upsetting is shown in Fig. 2. When the vibration frequency is $10 \mathrm{~Hz}$, the forming load curve is perfectly enveloped by the load cure without vibration. With vibration frequency increasing, the vibration-assisted load exceeds the nonvibration load curve. The higher the vibration frequency, the more obvious the exceeding phenomenon is. A comparison of the mean forming loads is displayed in Fig. 3. The mean forming load values of vibration-assisted processes are almost half of that of the non-vibration condition. The higher the vibration frequency, the lower the forming load will be. Therefore, it is indicated that even though 

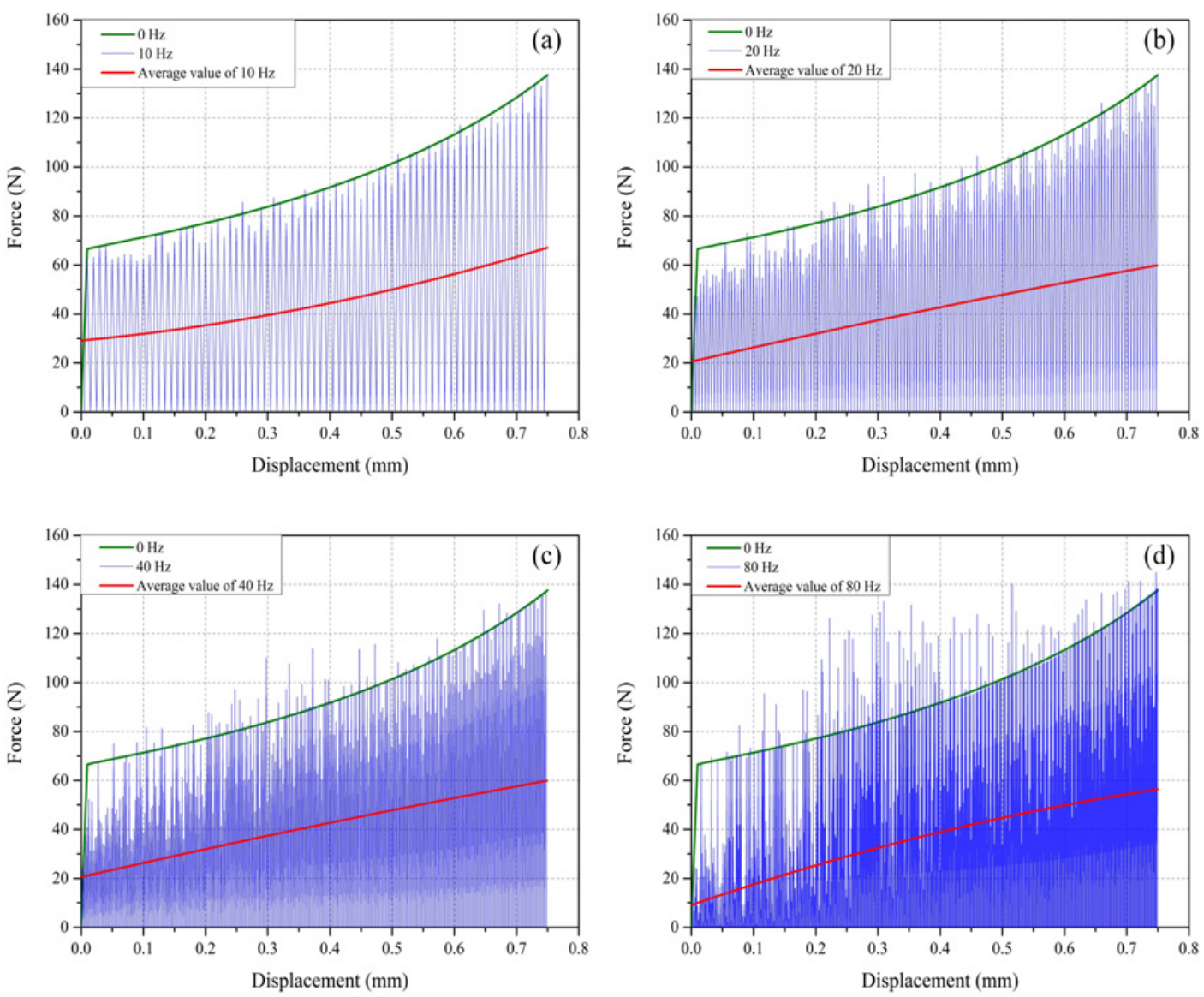

Figure 2. Load-displacement curves of vibration-assisted upsetting processes, all the feeding rates are $0.1 \mathrm{~mm} / \mathrm{s}$; the vibration frequency is (a) $10 \mathrm{~Hz}$, (b) $20 \mathrm{~Hz}$, (c) $40 \mathrm{~Hz}$ and (d) $80 \mathrm{~Hz}$.

increasing the vibration frequency can reduce the mean forming load significantly, the amplitude of the maximum load also increases obviously. At $80 \mathrm{~Hz}$, the maximum forming load is 1.6 times of the non-vibration forming load at the same deformation amount.

According to previous studies, the friction between the specimen and tools influences the bulging effect of upsetting significantly $[11,12]$. The higher the friction force at the interface between specimen and tools, the higher the ratio of the bulge radius (RB) to the initial radius (RI) will be. Since all the initial radii of specimens are the same, we can just compare the bulge radius. As shown in Fig. 4, the bulge radii at 0 and $10 \mathrm{~Hz}$ are almost the same, indicating that the vibration of $10 \mathrm{~Hz}$ has little influence on the interface friction. With the vibration frequency increasing, the bulge radii increase and are similar at 20, 40 and $80 \mathrm{~Hz}$. Therefore, it is demonstrated that the vibration increases the friction force between the specimen and tools, which agrees with the result reported by Hung et al. [4].

\subsubsection{Influence of feeding rate}

Figure 5 shows the forming load at different feeding rates. It is clearly revealed that the feeding rate has very limited influence on the forming load, both for the actual load and mean load. 


\section{MATEC Web of Conferences}

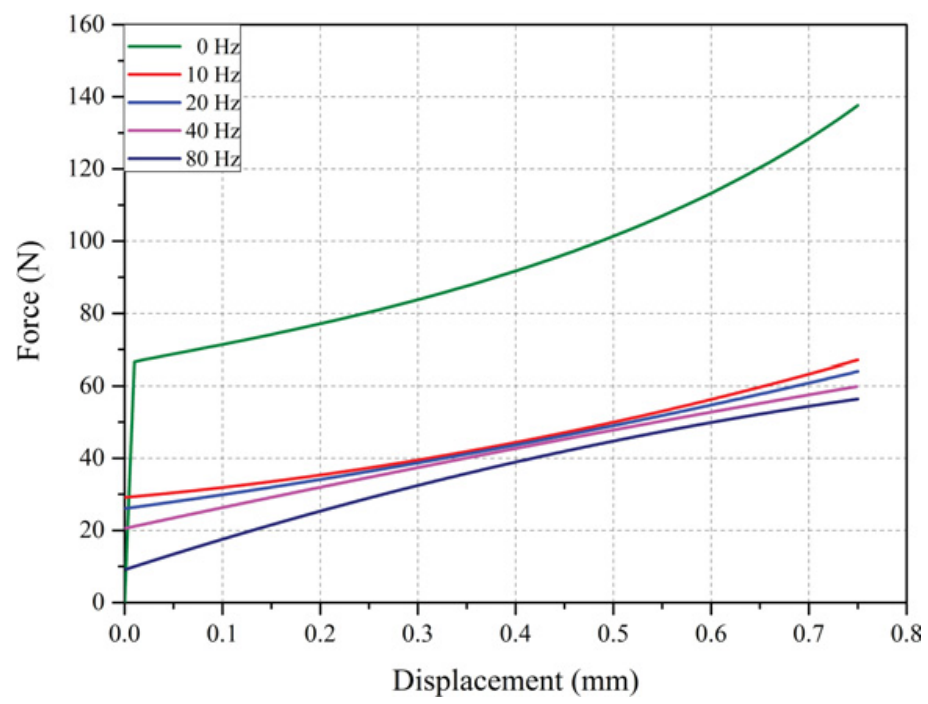

Figure 3. Influence of vibration frequency on the mean forming load of vibration-assisted upsetting.

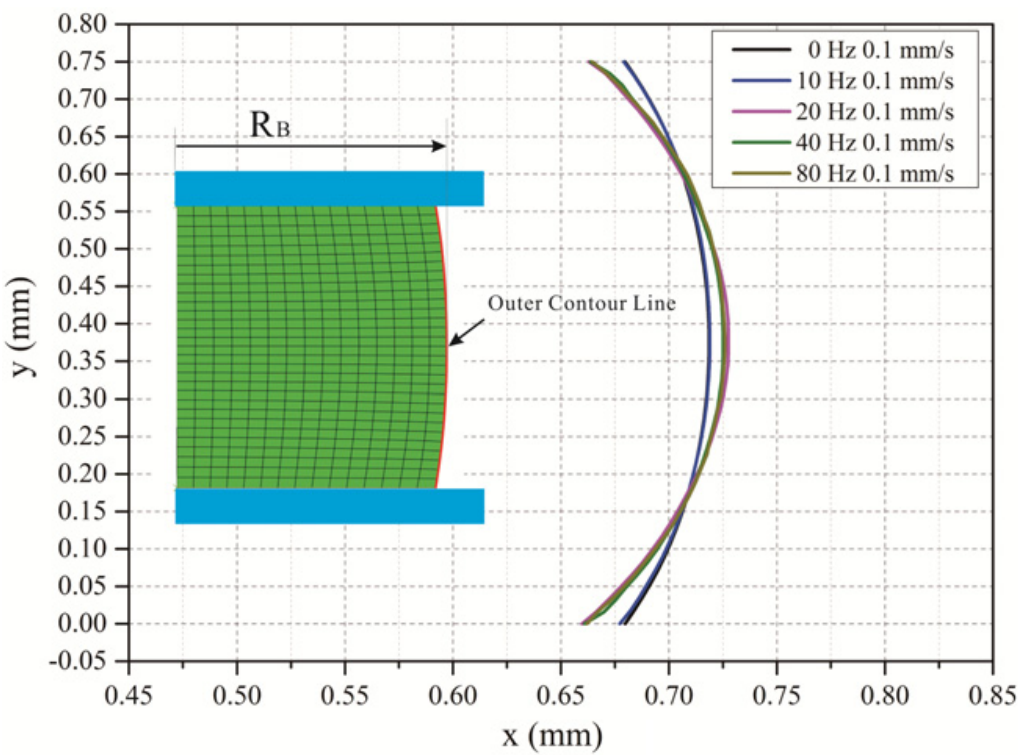

Figure 4. Influence of vibration frequency on the outer profile of compressed specimens.

Figure 6 shows the influence of feeding rate on the interface friction of upsetting processes. The bulge radius at $0.05 \mathrm{~mm} / \mathrm{s}$ is the smallest among all the three feeding rates while those of the 0.01 and $0.10 \mathrm{~mm} / \mathrm{s}$ are similar to each other. However, the difference between all three values is still slight. By combing Figs. 4 and 6, it can be found that the influence of vibration frequency is much more significant than that of the feeding rate.

Since the vibration frequency used in this study is significantly lower (lower than $100 \mathrm{~Hz}$ ) than that of ultrasonic (higher than $20 \mathrm{kHz}$ ), the temperature rise caused by the vibration can be neglected, which is considered as one of the important reasons for the reduction of forming load in 

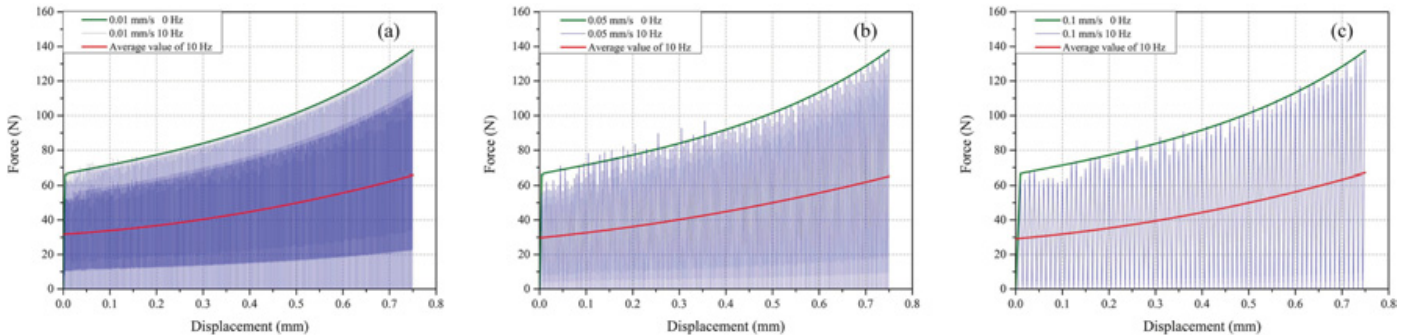

Figure 5. Influence of feeding rate on the forming load of vibration-assisted upsetting processes.

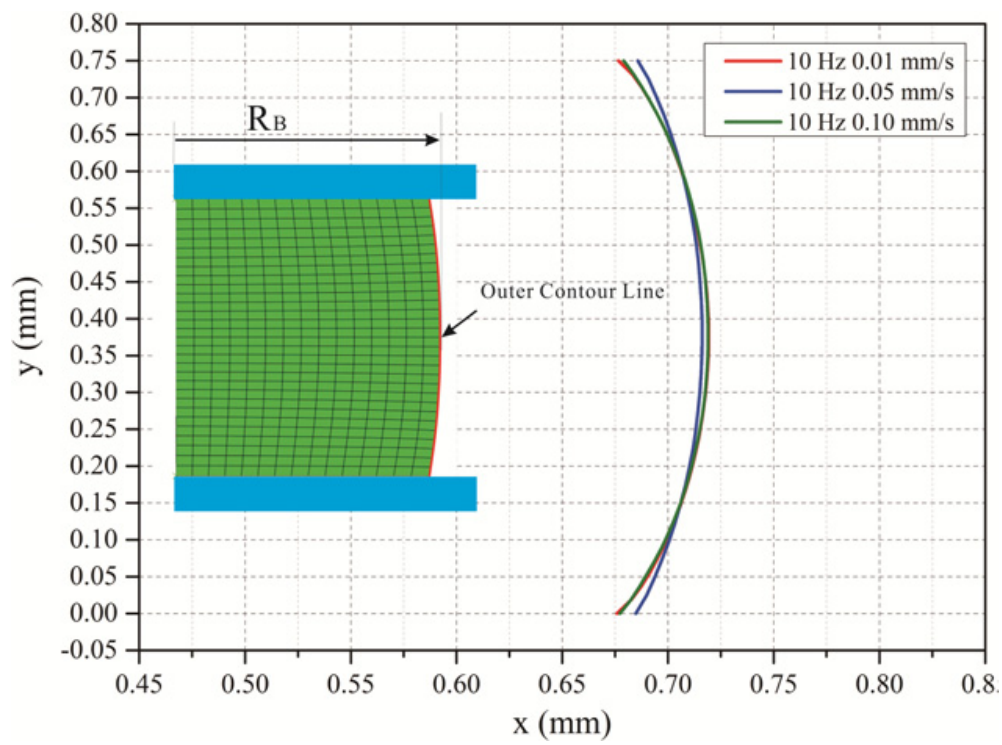

Figure 6. Influence of feeding rate on the outer profile of compressed specimens.

ultrasonic-assisted upsetting [4]. For most of the ultrasonic-assisted forming processes, the ultrasonic vibration is introduced by placing an ultrasonic transducer under the lower die while the upper die is moving downward at a constant speed. Under this condition, the reduction in mean forming force could be explained by the additional stress superposition, as suggested by Huang et al. [6]. In this study, the vibration is applied by the reciprocating motion of the upper die, and the forming load reduction mechanism seems to be different from that in ultrasonic-assisted processes. Therefore, further investigations are required to explain the deformation behaviour of metals in forming processes assisted by low-frequency vibrations.

\section{Conclusions}

The upsetting process assisted by low-frequency vibration was analysed based on finite element simulations, with the influence of vibration frequency and feeding rate on the forming load and interfacial friction discussed. Some conclusions can be drawn as follows.

(1) Low-frequency vibration can significantly reduce the mean forming load of upsetting processes. Increasing the vibration frequency can decrease the mean forming load, but increase the maximum amplitude of transient load. 


\section{MATEC Web of Conferences}

(2) Vibration increases the interfacial friction between billets and tools. The higher the frequency, the higher the friction will be.

(3) The feeding rate has very limited influence on the flow behaviour of billet, both for the forming load and interfacial friction.

This work was financially supported by the National Natural Science Foundation of China (Grant No. 51175202) and the New Century Talent Supporting Project by the Ministry of Education (Grant No. NCET-11-0185).

\section{References}

[1] A. Siddiq, T. El Sayed, Ultrasonics 52, 521 (2012)

[2] Y. Bai, M. Yang, J. Mater. Process. Tech. 213, 330 (2013)

[3] A.E. Eaves, A.W. Smith, W.I. Waterhouse, Ultrasonics 15, 162 (1975)

[4] J. Hung, Y. Tsai, C. Hung, Ultrasonics 46, 277 (2007)

[5] Y. Ashida, H. Aoyama, J. Mater. Process. Tech. 187, 118 (2007)

[6] Z. Huang, M. Lucas, M.J. Adams, Ultrasonics 40, 43 (2002)

[7] C. Bunget, G. Ngaile, Ultrasonics 51, 606 (2011)

[8] B. Langenecker, IEEE Trans. Son. Ultrason. 15, 1 (1966)

[9] O. Izumi, K. Oyama, Trans. Jpn. Inst. Met. 7, 158 (1966)

[10] Y. Daud, M. Lucas, J. Mater. Process. Tech. 186, 179 (2007)

[11] R. Ganesh Narayanan, M. Gopal, A. Rajadurai, J. Test. Eval. 36, 1 (2008)

[12] L. Deng, X.T. Li, J.S. Jin, J. Mater. Process. Tech. 214, 2276 (2014) 